Li Junying (Orcid ID: 0000-0002-5782-2051)

Chen Zhaozhao (Orcid ID: 0000-0002-2188-1367)

Wang Hom-Lay (Orcid ID: 0000-0003-4238-1799)

\title{
Does flap opening or not influence the accuracy of semi-guided implant placement in partially edentulous sites?
}

\author{
Junying Li, DDS, MS ${ }^{1,2}$, Zhaozhao Chen, DDS, $\mathrm{MS}^{1,2}$, Hsun-Liang Chan, DDS, MS ${ }^{1}$, Khaled \\ Sinjab, DDS ${ }^{1}$, Haiyang Yu, DDS, $\mathrm{PhD}^{2}$, Hom-Lay Wang, DDS, MS, $\mathrm{PhD}^{1}$
}

\author{
Authors' affiliations: \\ ${ }^{1}$ Department of Periodontics and Oral Medicine, University of Michigan School of Dentistry, \\ Ann Arbor, MI, USA. \\ ${ }^{2}$ State Key Laboratory of Oral Diseases, National Clinical Research Center for Oral Disease, \\ Department of Prosthodontics, West China Hospital of Stomatology, Sichuan University, \\ Chengdu, People’s Republic of China
}

\section{Corresponding Author:}

Hom-Lay Wang, DDS, MSD, PhD.

School of Dentistry, University of Michigan, Ann Arbor, MI, USA

1011 North University Avenue

Ann Arbor, Michigan, 48109-1078, USA

TEL: (734) 763-3383; FAX: (734) 936-0374

E-MAIL: homlay@umich.edu

This is the author manuscript accepted for publication and has undergone full peer review but has not been through the copyediting, typesetting, pagination and proofreading process, which may lead to differences between this version and the Version of Record. Please cite this article as doi: $10.1111 /$ cid.12847

This article is protected by copyright. All rights reserved. 
Word Count: 2302

Tables: 3; Figures: 5

Running Title: Accuracy of flap/flapless guided surgery

Keywords: dental implants; computer-assisted; flapless implant surgery; stereolithography

Conflict of interest and source of funding: The authors declare no conflicts of interest, either directly or indirectly, in the information or products listed in the paper. This paper was partially supported by the University of Michigan Periodontal Graduate Students Research Funds.

\section{Contribution of each author}

\begin{tabular}{|l|l|}
\hline Author & Contributions \\
\hline Junying Li & Study design, digital implant planning, perform implant surgery, data \\
measurement, statistics, drafting article, final approval of the manuscript
\end{tabular}

This article is protected by copyright. All rights reserved. 


\begin{tabular}{|l|l|}
\hline & manuscript \\
\hline Hom-Lay Wang & $\begin{array}{l}\text { Study design, critical revising of the paper, final approval of the } \\
\text { manuscript, securing the funding of research }\end{array}$ \\
\hline
\end{tabular}

This article is protected by copyright. All rights reserved. 


\begin{abstract}
Objective: To investigate the effect of open-flap or flapless approaches on the accuracy of implant placement partially guided by tooth-supported surgical templates. Material and methods: A total of 36 edentulous sites were selected from 7 human cadaver heads. Following the preoperative implant planning using Blue Sky Plan, surgical guides were fabricated by an inoffice desktop 3D printer. All the sites were randomly divided into 2 groups: flapless approach $(\mathrm{n}=18)$, and open-flap approach $(\mathrm{n}=18)$. After guided osteotomy preparation with subsequent freehand implant placement, digital intraoral scanning was performed to obtain post-operative implant positions. Based on the image registration, the deviations between the planned and actual implant position were measured and compared. Results: Statistically significant variance differences between the two approaches were found in the global coronal (Open-flap: $0.86 \pm 0.23$ mm; Flapless: $1.3 \pm 0.62 \mathrm{~mm} ; P<.001$ ), global apical (Open-flap: $1.38 \pm 0.37 \mathrm{~mm}$; Flapless: 1.9 $\pm 0.78 \mathrm{~mm} ; P=.002$ ), and depth (Open-flap: $0.59 \pm 0.34 \mathrm{~mm}$; Flapless $0.89 \pm 0.78 \mathrm{~mm} ; P<.001$ ) deviations. The differences were not significant regarding lateral (coronal and apical) and angular deviations. Conclusions: In semi-guided implant surgery, the open-flap and flapless approaches demonstrate similar lateral and angular deviations. The open-flap group shows better depth control when manually inserting the implant.
\end{abstract}




\section{INTRODUCTION}

Over the past decades, computer-assisted implant placement using static stereolithographic guides has been widely accepted. In this workflow, implant position can be pre-operatively planned in a computer software based on patient's cone beam computed tomography (CBCT) data as well as optical scan, and the implant surgery could be performed accordingly with the use of a template. Showing better accuracy compared with freehand drilling, ${ }^{1-3}$ guided surgery can also reduce the duration of treatment, ${ }^{4}$ optimize the integration of prosthetic and surgical design, ${ }^{5}$ and facilitate the application of flapless surgery. ${ }^{6}$

Even under the guidance, deviations between the pre-operative plan and post-operative implant position are still inevitable. According to a recent systematic review on the accuracy of stereolithographic surgical guides in clinical situations, ${ }^{7}$ these deviations range from $1.04 \mathrm{~mm}$ to $1.44 \mathrm{~mm}$ (mean: $1.2 \mathrm{~mm}$ ) at the coronal level, 1.28 to $1.58 \mathrm{~mm}$ (mean: $1.4 \mathrm{~mm}$ ) at the apical level, and $3^{\circ}$ to $3.96^{\circ}$ (mean: $3.5^{\circ}$ ) for the angle. Inaccuracy of guided surgery may be accumulated by each step from image acquisition to implant placement and influenced by varied factors such as the use of conventional multi-slice CT or CBCT, ${ }^{8}$ support of surgical template, ${ }^{9,10}$ guide system, ${ }^{11}$ operator experience, ${ }^{12}$ and fully guided or partially guided systems. ${ }^{13,14}$

When performing the guided implant surgery, whether or not the surgical technique (flapless/flapped) would influence the accuracy of implant placement is unclear. Some studies

showed no significant difference between these two modalities. ${ }^{15,16}$ In another study by Cassetta et al., the flapless approach demonstrated significantly worse accuracy at the apical level but 
better accuracy at the coronal level. ${ }^{17}$ Recently, a meta-analysis ${ }^{18}$ of three studies ${ }^{4,9,15}$ showed superior accuracy in the flapless approach compared to that in the open-flap modality. It should be noted that different types of surgical guide could be a confounding factor in these previous studies. To be more specific, in all the above studies, the open-flap group exclusively used bonesupported guides while the flapless group was guided by mucosa- or tooth-supported templates. Actually, in the clinic, flap approach is determined when a mucosa-supported or a bone supported guide is chosen. So, to test the effect of flap approach and make confounders well controlled, the tooth-supported guide is the only selection. Yet, to the best of our knowledge, only one study by Behneke et al. ${ }^{19}$ used tooth-supported templates in partially edentulous sites and provided date from both flapless and flapped groups. In this study, slightly higher values for the flapless approach compared with the flap group were shown in all parameters (global coronal, global apical and angular), and a tendential difference with borderline significance was found only in the global coronal deviations between these two groups. However, this study was done under both fully- and partially-guided procedures, which could be a confounding factor since fully guided surgery offers more accuracy than partially-guided surgery.

Therefore, the aim of this study was to investigate the overall range of implant deviations in partially implant guided surgery using tooth-supported templates with or without flaps elevation. Our hypothesis was that partially guided implant placement by the open-flap approach is as accurate as that by the flapless approach. 


\section{MATERIAL AND METHODS}

\section{Specimen screening}

This study, approved by the Institutional Review Boards of the University of Michigan (IRB\#HUM00134643), was performed in the Department of Periodontics and Oral Medicine. Fresh cadaver heads without fixation were used to simulate the clinical situation. Kept frozen ( 20 Celsius degree) after harvested from donors, these specimens were obtained from the Anatomy Department of the University of Michigan. Before the study, the heads were deforested and screened. The selection of available specimen was based on the following criteria: 1) partially edentulous, 2) enough teeth with no visible mobility, and 3) residual crest bone width of $\geq 6 \mathrm{~mm}$ (confirmed by CBCT). A total of 7 cadaver heads, 10 jaws, and 36 implant sites were selected for this study. The study design is presented in Figure 1.

\section{Preoperative Implant planning}

Each cadaver head received an intraoral scan by TRIOS (3Shape, Copenhagen, Denmark) and a CBCT scan using 3D Accuitomo 170 (J Morita, Kyoto, Japan) with a standard setting (5 $\mathrm{mA}, 90 \mathrm{kVp}, 17.5 \mathrm{sec}$, voxel size of $0.27 \mathrm{~mm}$, and field of view of $140 * 100 \mathrm{~mm})$. Intraoral scan and CBCT images were then converted into standard triangle language (STL) files and digital imaging and communications in medicine (DICOM) files, respectively. The implant planning of all sites was carried out in Blue Sky Plan3 (Version 3.40.5, Blue Sky Bio, IL, US) by one calibrated dentist. STL file and DICOM file of each jaw were imported and superimposed automatically by matching the mutual anatomical structures of teeth. Then the accuracy of 
alignment was checked in the cross-sectional view. When necessary, a manual alignment would be performed to achieve the best superimposition accuracy. A virtual tooth was planned on each implant site to mimic the definitive prostheses, and the 3D position of all implants $(3.7 \times 13 \mathrm{~mm}$, Tapered Screw-Vent; Zimmer/Biomet3i, West Palma Beach, FL) were designed considering both bone volume and virtual restoration position. When a prosthetic-driven implant position was not allowed, the implant would be positioned within the bone rather than following the virtual tooth position. All the implant platform positions were set at the level of the bone crest. After implant planning, tooth-supported surgical templates were designed involving at least 2-3 adjacent teeth for guide stability and fabricated by an in-office desktop 3D printer (Form 2 SLA 3D printer; Formlabs, Somerville, MA) using a liquid photo-polymerized resin (Clear; Formlabs,

Somerville, MA). ${ }^{20,21}$ Then the templates were washed twice by alcohol. After supports were removed, metal sleeves (4.2 Guide Tube; Blue Sky Bio, LLC, Grayslake, IL) were fitted into tubes before the final light curing.

\section{Surgical protocol}

All the surgical fields were randomly allocated to two groups (open-flap or flapless) before the surgery according to a computer-generated number sheet. Surgical templates were tried on cadaver jaws to confirm its accurate fitting. For the open-flap group (Figure $2 \mathrm{a}-\mathrm{c}$ ), fullthickness flaps were elevated at each site before drilling procedure. For the flapless group (Figure 2 d-f), soft tissue punches were performed before the guided osteotomy, and the thickness of mucosa was measured by a probe. All implant beds were prepared using guided- 
implant surgical kits (Zimmer Instrument Kit System and Tube Adapter Kit; Zimmer/Biomet3i, West Palma Beach, FL) according to the manufacturer's instructions. After the osteotomy, implants were inserted by handpiece with a torque of $35 \mathrm{~N}$ to the crest level. The correct implant depth was assessed visually in the open-flap group, while in the flapless group, a probe was used to assess the height of soft tissue above the implant platform, which should be equal to the mucosa thickness recorded prior. Since the fixture mount had a larger diameter than the implant, it was removed to prevent hampering the insertion procedure in the flapless group.

\section{Technique validation}

The optical scan was used for implant accuracy comparison according to methods proposed by previous studies. $^{20,22}$ Following implant placement, a digital impression was made using the fixture mount as a scanbody, and the data was saved as STL file then imported into a dental CAD software (Exocad, Exocad GmbH, Darmstadt, Germany). The pre-operative scan in implant planning project was exported from Blue Sky Plan then imported into Exocad. In the dental CAD software, the post-operative scan was superimposed to the pre-operative scan, color map was to verify the accuracy of superimposed of the two scans. The aligned post-operative scan was then exported from Exocad then imported into Blue Sky Plan for further measurements (Figure 3). To evaluate the accuracy of implant placement, deviations were determined using following parameters (Figures 4). The global deviation was calculated as the 3D distance of coronal/apical center between the planned and actual implant. The angular deviation was defined as the $3 \mathrm{D}$ angle between the centerlines of the two positions. The depth deviation was the 
decomposition of the global deviation in part along the axis of the planned implant, and the lateral deviation was that in part perpendicular to it. All the above parameters were used in absolute value. Additionally, to illustrate the direction of depth deviation, the depth deviation was also recorded as positive when the actual implant being coronal to the planning or negative when apical to the planning.

The aligning process and measurement were performed twice independently by two calibrated examiners (JYL and ZZC). The intraclass correlation coefficient (ICC) for interobserver reliability ranged from 0.83 to 0.91 , indicating a high agreement. The mean value of each measurement was calculated and used for statistical analysis.

\section{Statistical analysis}

All data were analyzed using a statistical software package (SPSS version 23.0). The statistical analysis was adopted from Bencharit et al. ${ }^{14}$ For the description of data, number of observations, mean, standard deviation (SD), 95\% confident interval (95\% CI), minimum (Min), maximum (Max) and range (Max-Min) were presented. Accuracy data were illustrated using box plots and one-tail F test was used to determine if the variance was significantly different between the two groups. The null hypothesis was that there is no deviation variance difference between the open-flap group and the flapless group. Significance for statistical analyses was set at $P<.01$.

\section{RESULTS}

This article is protected by copyright. All rights reserved. 
All implants were successfully placed and achieved a minimal insertion torque of 35 Ncm. Deviations between the digital plan and postoperative implant position for both groups were shown in Table 1 and Figure 5. The deviations in the open-flap group were $0.86 \pm 0.23$ $\mathrm{mm}$ at global-coronal level, $1.38 \pm 0.37 \mathrm{~mm}$ at global-apical level, $0.59 \pm 0.34 \mathrm{~mm}$ in depth (absolute value), $0.16 \pm 0.68 \mathrm{~mm}$ in depth when considering direction, $0.54 \pm 0.23 \mathrm{~mm}$ at lateralcoronal level, $1.19 \pm 0.45 \mathrm{~mm}$ at lateral-apical level, and $3.84 \pm 2.12$ degrees in axis. In flapless group, deviations were $1.3 \pm 0.62 \mathrm{~mm}$ at global-coronal level, $1.9 \pm 0.78 \mathrm{~mm}$ at global-apical level, $0.89 \pm 0.78 \mathrm{~mm}$ in depth (absolute value), $0.51 \pm 1.09 \mathrm{~mm}$ in depth when considering direction, $0.76 \pm 0.26 \mathrm{~mm}$ at lateral-coronal level, $1.53 \pm 0.71 \mathrm{~mm}$ at lateral-apical level, and 4.73 \pm 2.27 degrees in axis. Significantly different variance between open-flap and flapless surgeries was shown in global-coronal deviation $(P<.001)$, global-apical deviation $(P=.002)$, and depth deviation when considering direction $(P<.001)$ (Table 2).

\section{DISCUSSION}

Flapless approach is widely used in daily implant surgery, due to its preservation of tissue's blood supply, improved patients' comfort, and reduced treatment time. ${ }^{23}$ The use of static stereolithographic guides has been shown to facilitate the accuracy of flapless implant placement. ${ }^{6}$ However, in the cases lacking keratinized gingival tissue or requiring bone augmentation, the open-flap approach still cannot be avoided. ${ }^{24}$ The purpose of the present study was to find out whether the surgical technique (flapless/flapped) would affect the accuracy of 
partially guided implant surgery. Our results showed that, compared to the flapless approach, open-flap surgery has less variation in the global-coronal, global-apical deviations and the absolute value of depth deviation, while no significant difference was found in the lateral coronal/apical, the depth considering the direction and the angular deviations. Considering that the global deviation was decomposed into depth and lateral deviations, and there was no lateral deviation difference between two groups, it can be suggested that the worse accuracy in the flapless group was mainly derived from a greater depth deviation.

The poor depth control in the flapless group may rise from the step of implant insertion. Since a partially-guided system was used in this study, when place the implant fixture manually, the depth of implants could only be checked by visualization and this control is limited in the flapless group. In a fully-guided system, the fixture is guided through the sleeves during placement, and the hex orientation and depth can be controlled by scales on the implant carrier. ${ }^{25}$ Thus, placing an implant in a fully-guided may produce a different result on the accuracy of flapped/flapless approaches.

Previous studies reporting date on the accuracy of flapped/flapless guided implant surgery were summarized in Table 3.,11,15,16,19,26,27 There was only one study, by Behneke et al., has the similar design (comparing flapped to flapless in tooth-supported guided surgeries) with ours. ${ }^{19}$ In this retrospective clinic study, a mean lateral-coronal deviation of $0.36 \mathrm{~mm}$, a lateralapical deviation of $0.53 \mathrm{~mm}$ and an angular deviation of 2.11 degrees were found in the flapless group, while these values were $0.28 \mathrm{~mm}, 0.45 \mathrm{~mm} 2.08$ degrees in the open-flap group. 
Compared to our results, the deviations obtained in Behneke’s study were much less. Since we used a partially-guided system, the adopting of a fully-guided system in his study can partially explain this difference. Despite that, Behneke and his co-workers found no accuracy difference between open-flap and flapless approaches in terms of lateral deviations, which agrees with our observation. However, no data regarding depth deviation was reported in that study. Other studies, though have no data on open-flap tooth-supported guided surgery, reported the accuracy of flapless tooth-supported approach as a mean global-coronal deviation of 0.81 to $1.31 \mathrm{~mm}$, mean global-apical deviation of 0.95 to $1.62 \mathrm{~mm}$, and mean angular deviation of 2.91 to 3.5 degrees. $^{9,11}$

The major concern of the depth of an implant is the location of the rough/smooth surface junction (for tissue-level implants) or implant-abutment connection (for bone-level implants). The greater vertical deviation in flapless guided surgery may result in either a deeper or a shallower implant fixture position. It has been reported that placing the junction of rough and smooth surface or implant-abutment connection into a sub-crestal location demonstrated more peri-implant bone loss. ${ }^{28,29}$ On the other hand, a shallower implant position may lead to esthetic complication in anterior sites as well as the risk of exposure of rough surface, which may facilitate the development of peri-implant diseases. ${ }^{30,31}$

The results of the present study should be interpreted with caution due to the limited sample size. Moreover, no blinding was done during the surgery since the intervention is flap approaches. In addition, the cadaver design may demonstrate reduced deviations compared to 
real clinic situations due to the lack of bleeding and movement of the subject. Further studies should be done to assess the influence of open-flap/flapless on the accuracy of computer-assisted implant surgery with the fully-guided approach.

\section{CONCLUSION}

In semi-guided implant surgery, the open-flap and flapless approaches demonstrate similar lateral and angular deviations. The open-flap group shows better depth control when manually inserting the implant.

This article is protected by copyright. All rights reserved. 


\section{REFERENCES}

1. Noharet R, Pettersson A, Bourgeois D. Accuracy of implant placement in the posterior maxilla as related to 2 types of surgical guides: a pilot study in the human cadaver. $\mathrm{J}$ Prosthet Dent. 2014;112:526-532.

2. Vermeulen J. The Accuracy of Implant Placement by Experienced Surgeons: Guided vs Freehand Approach in a Simulated Plastic Model. Int J Oral Maxillofac Implants. 2017;32:617-624.

3. Chen Z, Li J, Sinjab K, Mendonca G, Yu H, Wang HL. Accuracy of flapless immediate implant placement in anterior maxilla using computer-assisted versus freehand surgery: A cadaver study. Clin Oral Implants Res. 2018;29:1186-1194.

4. Arısan V, Karabuda CZ, Özdemir T. Implant surgery using bone-and mucosa-supported stereolithographic guides in totally edentulous jaws: surgical and post-operative outcomes of computer-aided vs. standard techniques. Clin Oral Implants Res. 2010;21:980-988.

5. van Steenberghe D, Molly L, Jacobs R, Vandekerckhove B, Quirynen M, Naert I. The immediate rehabilitation by means of a ready-made final fixed prosthesis in the edentulous mandible: a 1-year follow-up study on 50 consecutive patients. Clin Oral Implants Res. 2004;15:360-365.

This article is protected by copyright. All rights reserved. 
6. Brodala N. Flapless surgery and its effect on dental implant outcomes. Int J Oral Maxillofac Implants. 2009;24 Suppl:118-125.

7. Tahmaseb A, Wu V, Wismeijer D, Coucke W, Evans C. The accuracy of static computeraided implant surgery: A systematic review and meta-analysis. Clin Oral Implants Res. 2018;29(suppl 16):416-435.

8. Arisan V, Karabuda ZC, Avsever H, Özdemir T. Conventional multi-slice computed tomography (CT) and cone-beam CT (CBCT) for computer-assisted implant placement. Part I: Relationship of radiographic gray density and implant stability. Clin Implant Dent Relat Res. 2013;15:893-906.

9. Ozan O, Turkyilmaz I, Ersoy AE, McGlumphy EA, Rosenstiel SF. Clinical accuracy of 3 different types of computed tomography-derived stereolithographic surgical guides in implant placement. J Oral Maxillofac Surg. 2009;67:394-401.

10. Turbush SK, Turkyilmaz I. Accuracy of three different types of stereolithographic surgical guide in implant placement: an in vitro study. J Prosthet Dent. 2012;108:181-188.

11. Arısan V, Karabuda ZC, Özdemir T. Accuracy of two stereolithographic guide systems for computer-aided implant placement: a computed tomography-based clinical comparative study. J Periodontol. 2010;81:43-51.

This article is protected by copyright. All rights reserved. 
12. Cushen SE, Turkyilmaz I. Impact of operator experience on the accuracy of implant placement with stereolithographic surgical templates: an in vitro study. J Prosthet Dent. 2013;109:248-254.

13. Kuhl S, Zurcher S, Mahid T, Muller-Gerbl M, Filippi A, Cattin P. Accuracy of full guided vs. partially-guided implant surgery. Clin Oral Implants Res. 2013;24:763-769.

14. Bencharit S, Staffen A, Yeung M, Whitley D 3rd, Laskin DM, Deeb GR. In vivo toothsupported implant surgical guides fabricated with desktop stereolithographic printers: fully guided surgery is more accurate than partially guided surgery. J Oral Maxillofac Surg Off J Am Assoc Oral Maxillofac Surg. 2018;76:1431-1439.

15. Ersoy AE, Turkyilmaz I, Ozan O, McGlumphy EA. Reliability of implant placement with stereolithographic surgical guides generated from computed tomography: clinical data from 94 implants. J Periodontol. 2008;79:1339-1345.

16. Valente F, Schiroli G, Sbrenna A. Accuracy of computer-aided oral implant surgery: a clinical and radiographic study. Int J Oral Maxillofac Implants. 2009;24:234-242.

17. Cassetta M, Stefanelli LV, Giansanti M, Di Mambro A, Calasso S. Accuracy of a computeraided implant surgical technique. Int J Periodontics Restorative Dent. 2013;33:317-325.

This article is protected by copyright. All rights reserved. 
18. Zhou W, Liu Z, Song L, Kuo CL, Shafer DM. Clinical factors affecting the accuracy of guided implant surgery-A systematic review and meta-analysis. J Evid-Based Dent Pract. 2018;18:28-40.

19. Behneke A, Burwinkel M, Knierim K, Behneke N. Accuracy assessment of cone beam computed tomography-derived laboratory-based surgical templates on partially edentulous patients. Clin Oral Implants Res. 2012;23:137-143.

20. Deeb GR, Allen RK, Hall VP, Whitley D 3rd, Laskin DM, Bencharit S. How accurate are implant surgical guides produced with desktop stereolithographic. J Oral Maxillofac Surg Off J Am Assoc Oral Maxillofac Surg. 2017;75:2559.e1-2559.e8.

21. Whitley D, Eidson, RS, Rudek I, Bencharit S. In-office fabrication of dental implant surgical guides using desktop stereolithographic printing and implant treatment planning software: A clinical report. J Prosthet Dent. 2017;118, 256-263.

22. Cristache CM, Gurbanescu S. Accuracy evaluation of a stereolithographic surgical template for dental implant insertion using 3D superimposition protocol. Int $\mathrm{J}$ Dent. 2017;2017:4292081.

23. Scherer M, Ingel AP, Kendall K. Flap vs. Flapless: a practical guide with indications, recommendations, and techniques for effective planning and surgical placement of narrow diameter overdenture implants in the mandible. Implant Pract. 2014;7:36.

This article is protected by copyright. All rights reserved. 
24. Deeb JG, Bencharit S, Loschiavo CA, Yeung M, Laskin D, Deeb GR. Do implant surgical guides allow an adequate zone of keratinized tissue for flapless surgery? J Oral Maxillofac Surg Off J Am Assoc Oral Maxillofac Surg. 2018;76:2540-2550.

25. Mandelaris GA, Rosenfeld AL, King SD, Nevins ML. Computer-guided implant dentistry for precise implant placement: combining specialized stereolithographically generated drilling guides and surgical implant instrumentation. Int J Periodontics Restorative Dent. 2010;30:275-281.

26. Cassetta M, Stefanelli LV, Giansanti M, Di Mambro A, Calasso S. Depth deviation and occurrence of early surgical complications or unexpected events using a single stereolithographic surgi-guide. Int J Oral Maxillofac Surg. 2011;40:1377-1387.

27. Cassetta M, Di Mambro A, Giansanti M, Stefanelli L, Cavallini C. The intrinsic error of a stereolithographic surgical template in implant guided surgery. Int J Oral Maxillofac Surg. 2013;42:264-275.

28. Hammerle $\mathrm{CH}$, Bragger U, Burgin W, Lang NP. The effect of subcrestal placement of the polished surface of ITI implants on marginal soft and hard tissues. Clin Oral Implants Res. 1996;7:111-119.

This article is protected by copyright. All rights reserved. 
29. van Eekeren PJ, Tahmaseb A, Wismeijer D. Crestal bone changes around implants with implant-abutment connections at epicrestal level or above: systematic review and metaanalysis. Int J Oral Maxillofac Implants. 2016;31:119-124.

30. Bashutski JD, Wang HL. Common implant esthetic complications. Implant Dent. 2007;16:340-348.

31. Tomasi C, Sanz M, Cecchinato D, Pjetursson B, Ferrus J, Lang NP, et al. Bone dimensional variations at implants placed in fresh extraction sockets: a multilevel multivariate analysis. Clin Oral Implants Res. 2010;21:30-36.

This article is protected by copyright. All rights reserved. 
Table 1. Implant position deviations ( $\mathrm{mm})$ in flapped group and flapless group

\begin{tabular}{|c|c|c|c|c|c|c|c|c|}
\hline & & Global-coronal & Global-apical & Depth1 & Depth2 & Angular & Lateral-coronal & Lateral-apical \\
\hline & Mean & 0.86 & 1.38 & 0.16 & 0.59 & 3.84 & 0.54 & 1.19 \\
\hline & SD & 0.23 & 0.37 & 0.68 & 0.34 & 2.12 & 0.23 & 0.45 \\
\hline & Median & 0.86 & 1.35 & 0.26 & 0.58 & 3.83 & 0.54 & 1.19 \\
\hline & Min - Max & $0.15-1.55$ & $0.69-2.20$ & $-1.44-0.92$ & $0.05-1.44$ & $0.67-8.41$ & $0.11-1.03$ & $0.09-2.14$ \\
\hline & Range & 1.04 & 1.51 & 2.35 & 1.39 & 7.74 & 0.92 & 2.05 \\
\hline & $95 \%$ CI & $0.75-0.97$ & $1.20-1.57$ & $-0.18-0.49$ & $0.42-0.76$ & $2.78-4.89$ & $0.42-0.65$ & $0.96-1.41$ \\
\hline & Mean & 1.30 & 1.9 & 0.51 & 0.89 & 4.73 & 0.76 & 1.53 \\
\hline & SD & 0.62 & 0.78 & 1.09 & 0.78 & 2.27 & 0.26 & 0.71 \\
\hline Flapless & Median & 1.19 & 1.73 & 0.31 & 0.59 & 4.26 & 0.73 & 1.39 \\
\hline & Min - Max & $0.56-2.61$ & $0.76-2.97$ & $-1.04-2.55$ & $0.07-2.55$ & $1.51-8.08$ & $0.34-1.17$ & $0.53-2.83$ \\
\hline & Range & 2.05 & 2.21 & 3.59 & 2.48 & 6.57 & 0.83 & 2.30 \\
\hline
\end{tabular}

\section{TABLES}

This article is protected by copyright. All rights reserved. 
SD, standard deviation; Min, minimum; Max, maximum; CI, confidence interval

Depth1, depth when considering direction; depth2, absolute value of depth 
Table 2. Test of variance for deviations ( $\mathrm{mm}$ ) between flapped and flapless group

\begin{tabular}{|c|c|c|c|c|c|c|c|c|c|c|c|c|c|c|}
\hline \multirow[b]{2}{*}{$\begin{array}{l}\text { Grou } \\
\text { p }\end{array}$} & \multicolumn{2}{|c|}{$\begin{array}{l}\text { Global- } \\
\text { coronal }\end{array}$} & \multicolumn{2}{|c|}{ Global-apical } & \multicolumn{2}{|c|}{ Depth 1} & \multicolumn{2}{|c|}{ Depth 2} & \multicolumn{2}{|c|}{ Angular } & \multicolumn{2}{|c|}{ Lateral-corona } & \multicolumn{2}{|c|}{ Lateral-apical } \\
\hline & $\begin{array}{c}\text { Flap } \\
\text { ped }\end{array}$ & $\begin{array}{c}\text { Flapl } \\
\text { ess }\end{array}$ & $\begin{array}{c}\text { Flap } \\
\text { ped }\end{array}$ & $\begin{array}{c}\text { Flapl } \\
\text { ess }\end{array}$ & $\begin{array}{c}\text { Flap } \\
\text { ped }\end{array}$ & $\begin{array}{c}\text { Flapl } \\
\text { ess }\end{array}$ & $\begin{array}{c}\text { Flap } \\
\text { ped }\end{array}$ & $\begin{array}{c}\text { Flapl } \\
\text { ess }\end{array}$ & $\begin{array}{c}\text { Flap } \\
\text { ped }\end{array}$ & $\begin{array}{c}\text { Flapl } \\
\text { ess }\end{array}$ & $\begin{array}{c}\text { Flap } \\
\text { ped }\end{array}$ & $\begin{array}{c}\text { Flapl } \\
\text { ess }\end{array}$ & $\begin{array}{c}\text { Flapp } \\
\text { ed }\end{array}$ & Flapless \\
\hline $\begin{array}{l}\text { Varia } \\
\text { nce }\end{array}$ & 0.05 & 0.39 & 0.14 & 0.6 & 0.46 & 1.18 & 0.12 & 0.61 & 4.51 & 5.13 & 0.05 & 0.07 & 0.21 & 0.51 \\
\hline $\mathbf{P}$ & \multicolumn{2}{|c|}{$<0.001^{*}$} & \multicolumn{2}{|c|}{$0.002^{*}$} & \multicolumn{2}{|c|}{0.029} & \multicolumn{2}{|c|}{$<0.001^{*}$} & \multicolumn{2}{|c|}{0.397} & \multicolumn{3}{|c|}{0.291} & 0.035 \\
\hline
\end{tabular}

* Statistical difference was observed between groups (flapped/flapless) $(\mathrm{p}<0.01)$

Depth1, depth when considering direction; depth2, absolute value of depth 
Table 3. Summary of deviations in guided implant placement from literatures involving flap and flapless approach for comparison

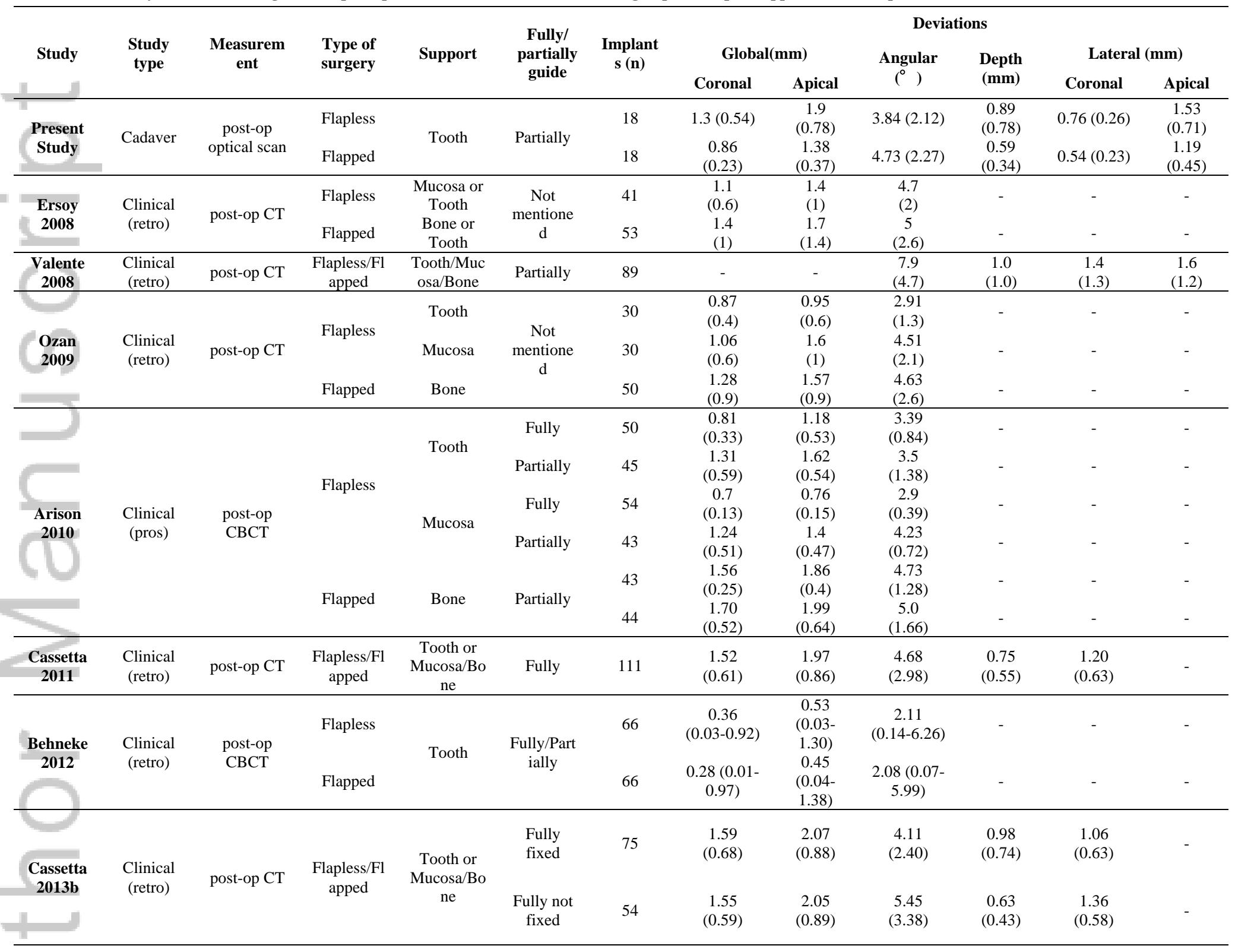




\section{FIGURE LEDGENDS}

Figure 1. Study design

Figure 2. Surgical procedures. (a-c) Open-flap group. (d-f) Flapless group

Figure 3. Workflow of superimposing pre- and post-operative data

Figure 4. Measurements of deviations

Figure 5. Box plot showing median, quartile, and extreme values of deviations

This article is protected by copyright. All rights reserved. 


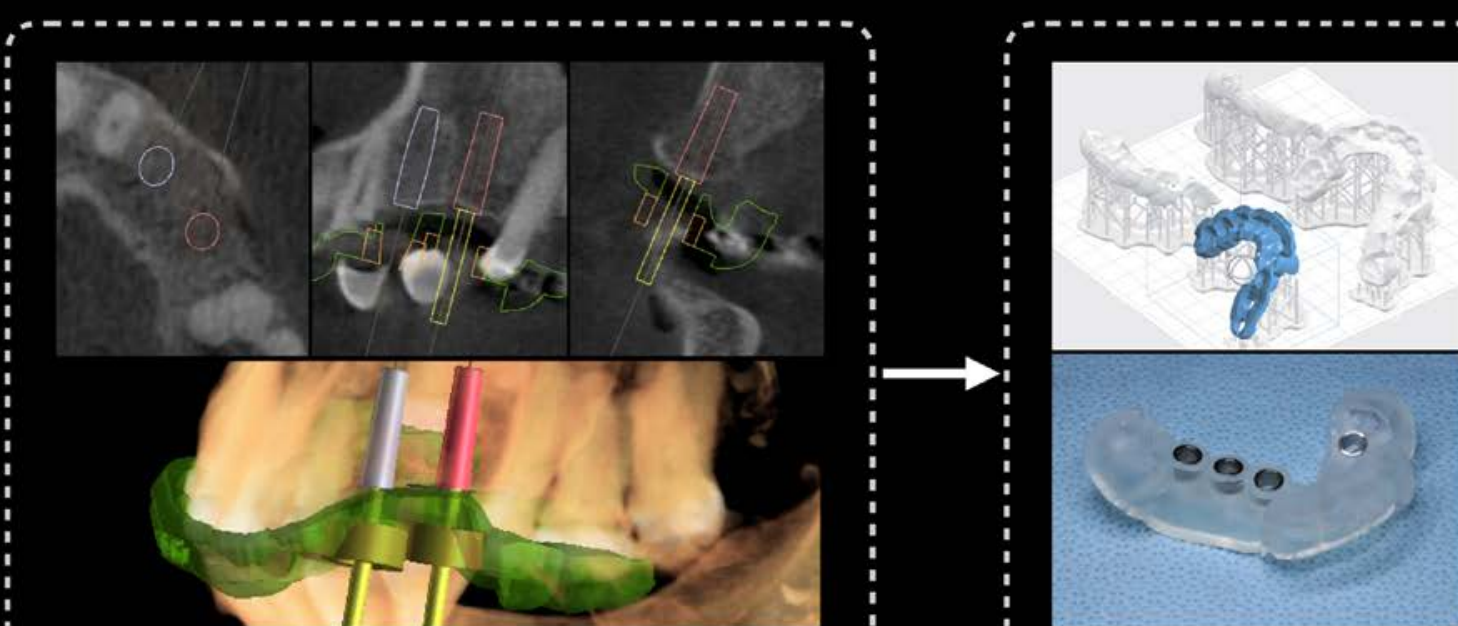

Digital planning
Guide fabrication

\section{Guide fabrication}

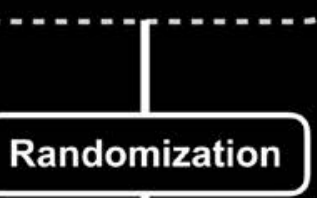

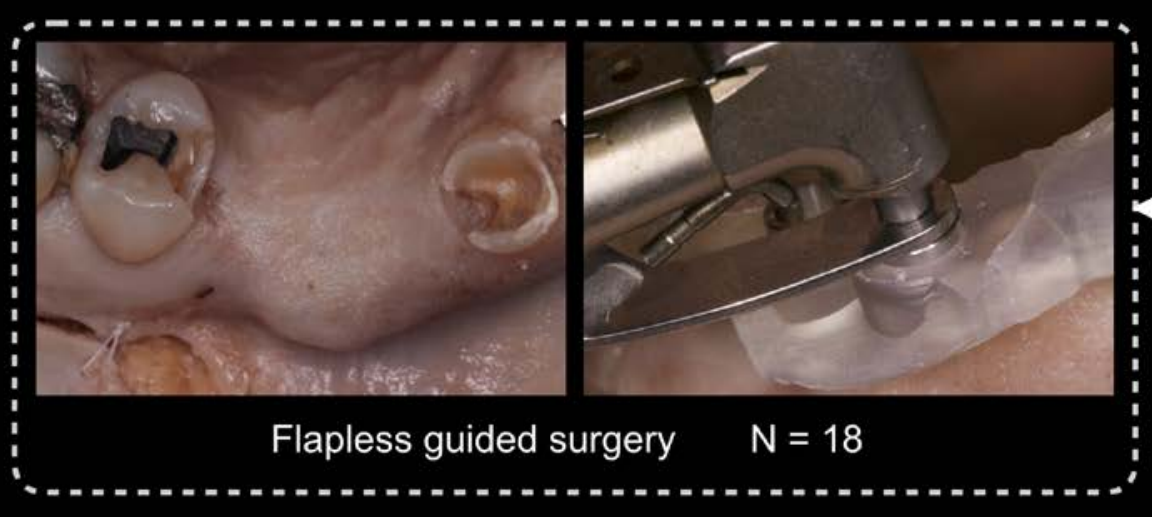
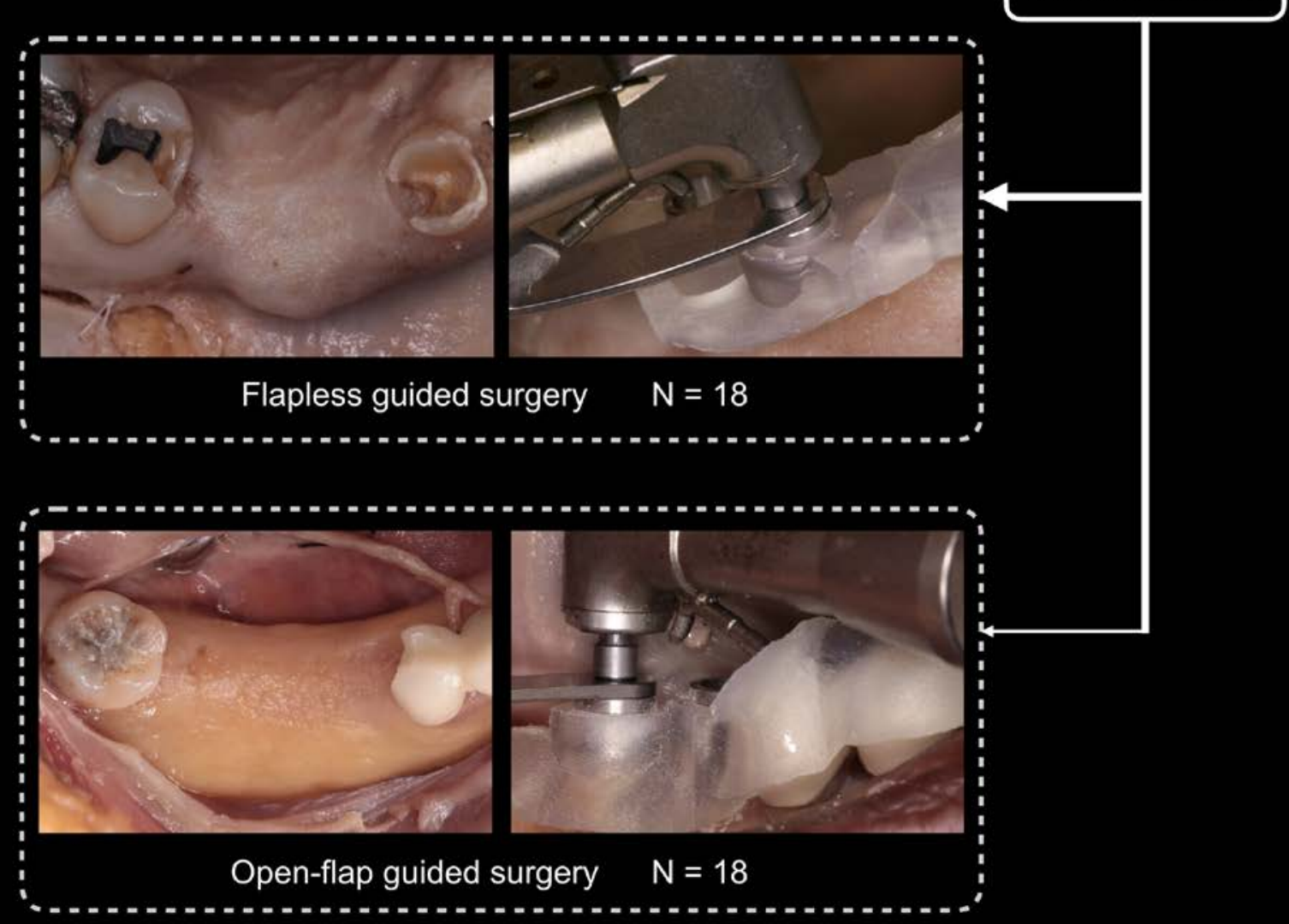

This article is protected by copyright. All rights reserved. 


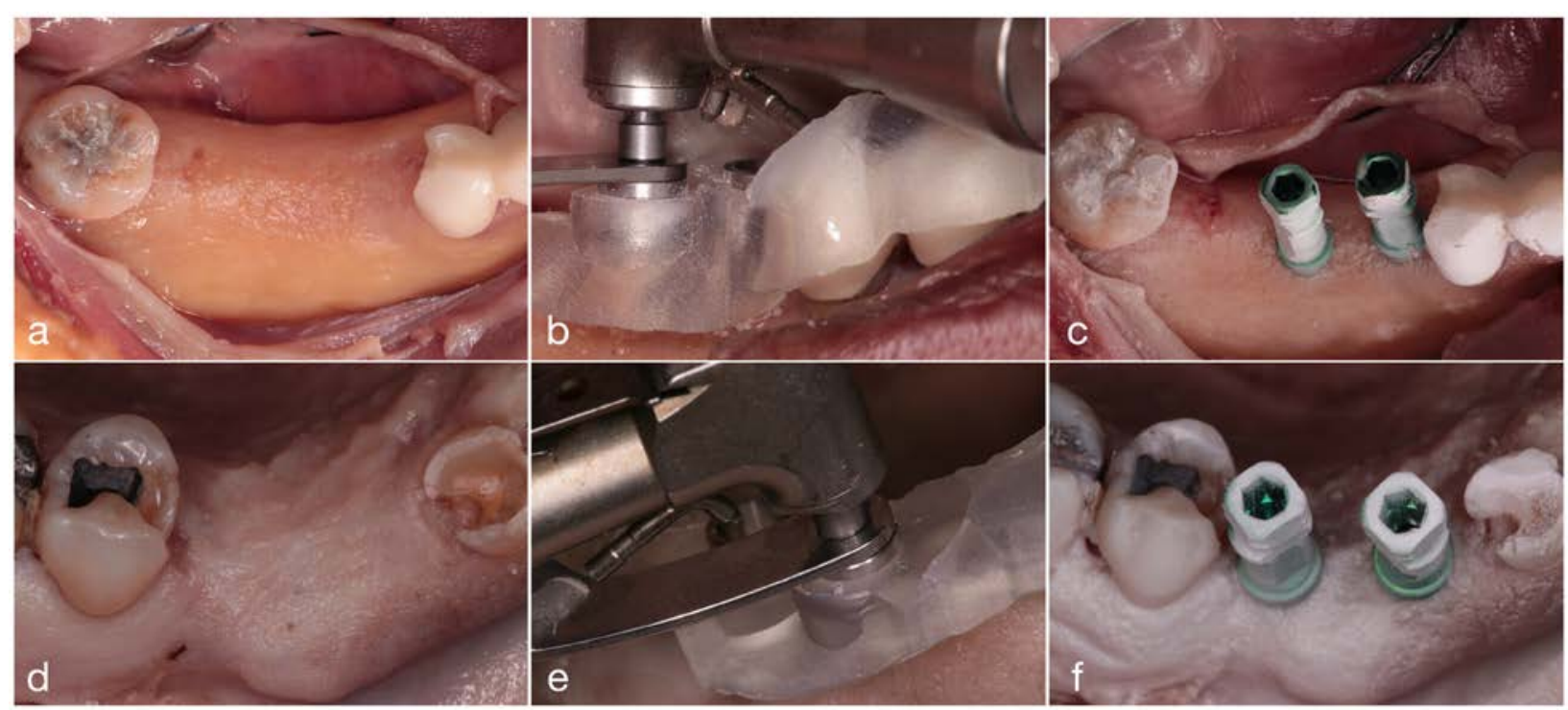

This article is protected by copyright. All rights reserved. 


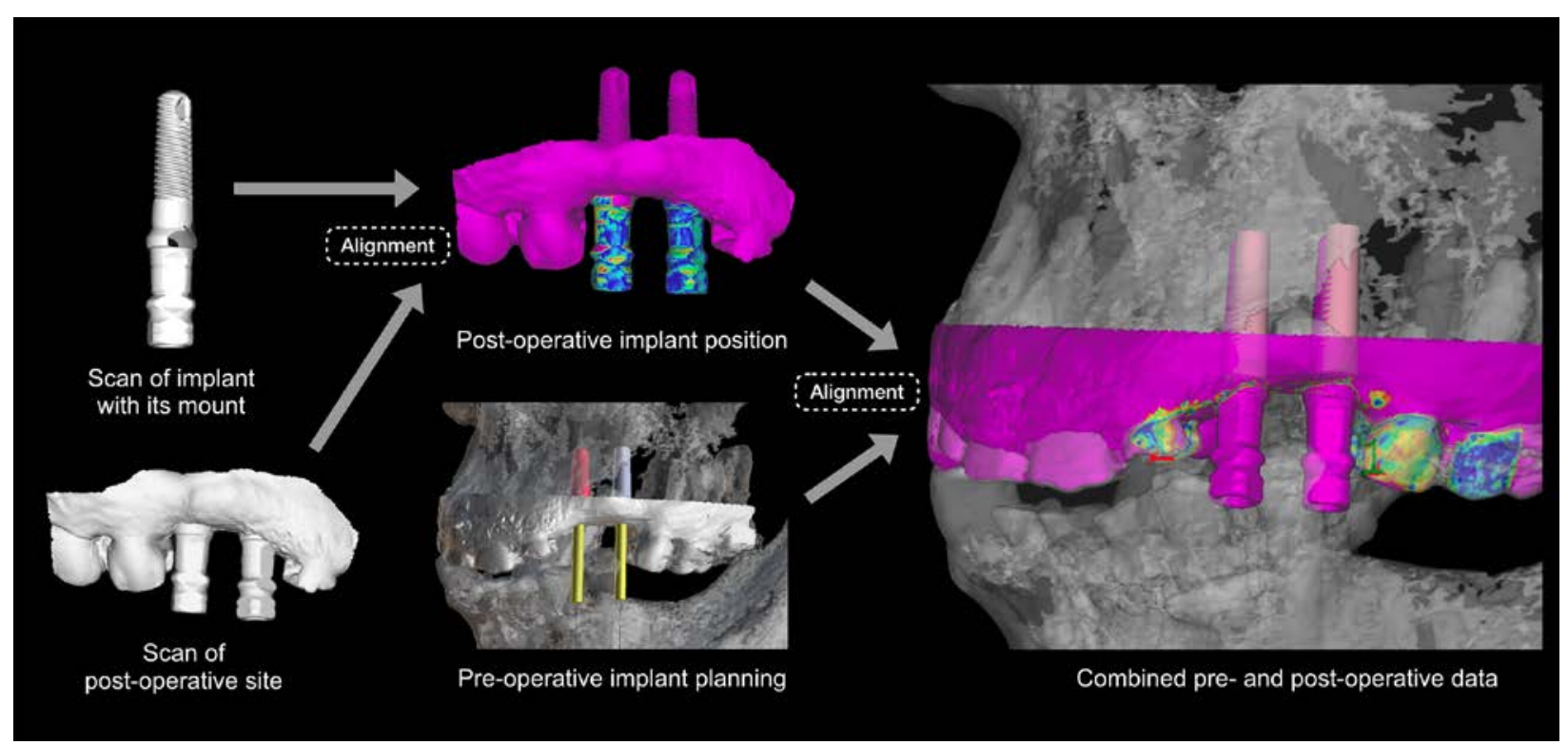

This article is protected by copyright. All rights reserved. 


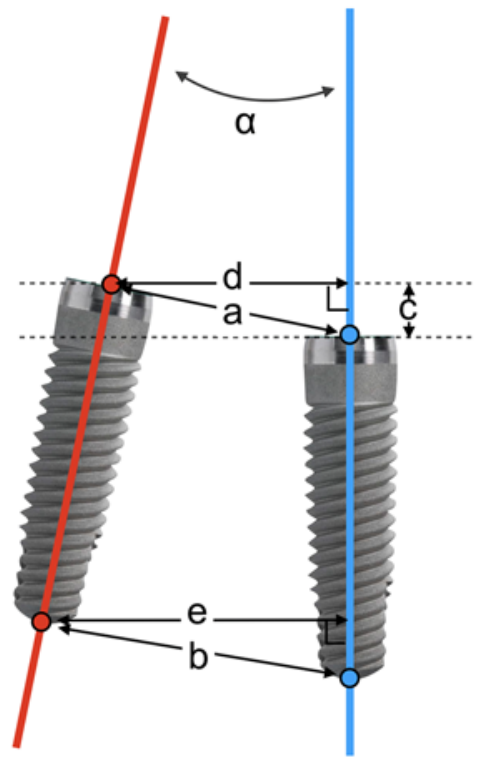

a: Global coronal deviation

b: Global apical deviation

c: Depth deviation

d: Lateral coronal deviation

e: Lateral apical deviation

a: Angular deviation

Actual position Planned position 


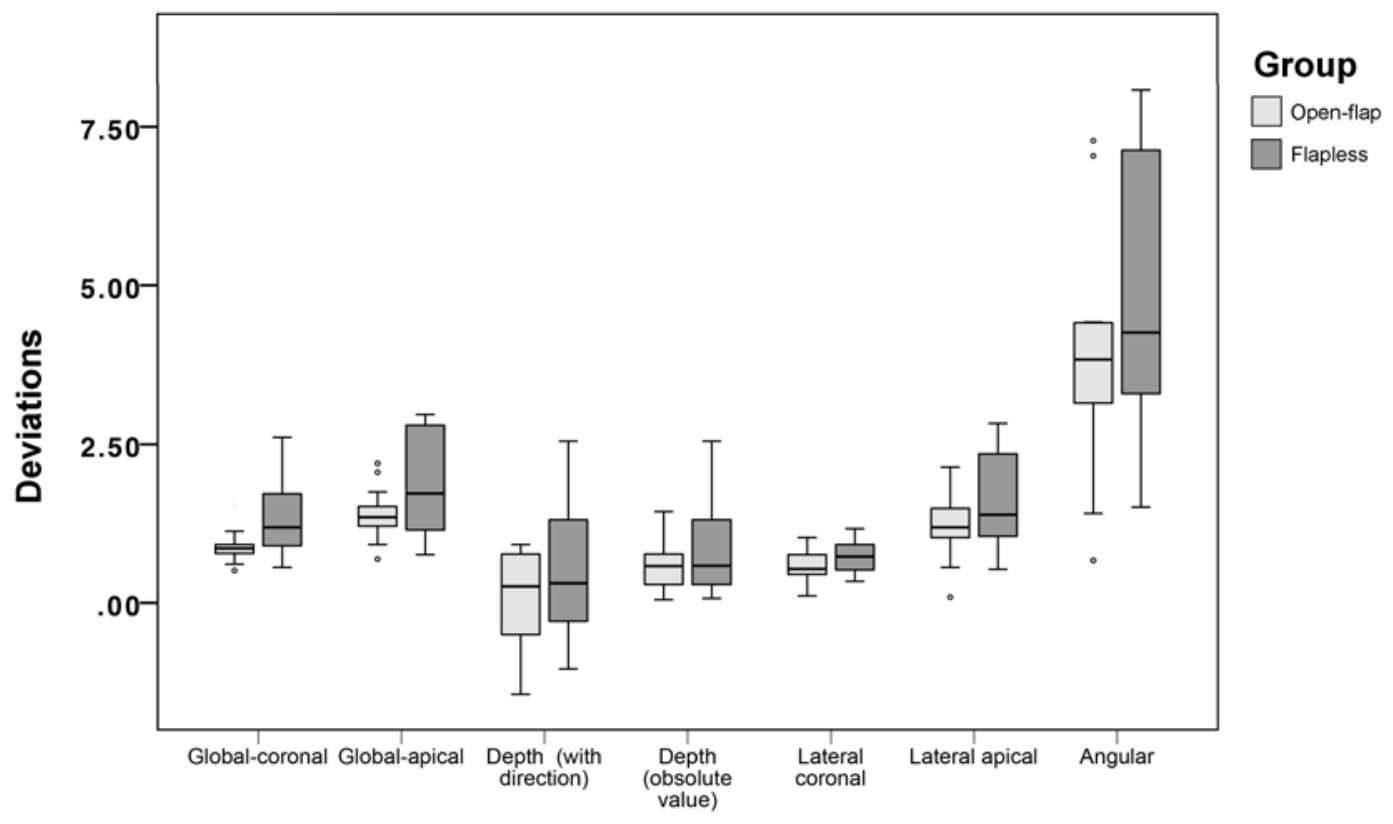

This article is protected by copyright. All rights reserved. 



Guide fabrication
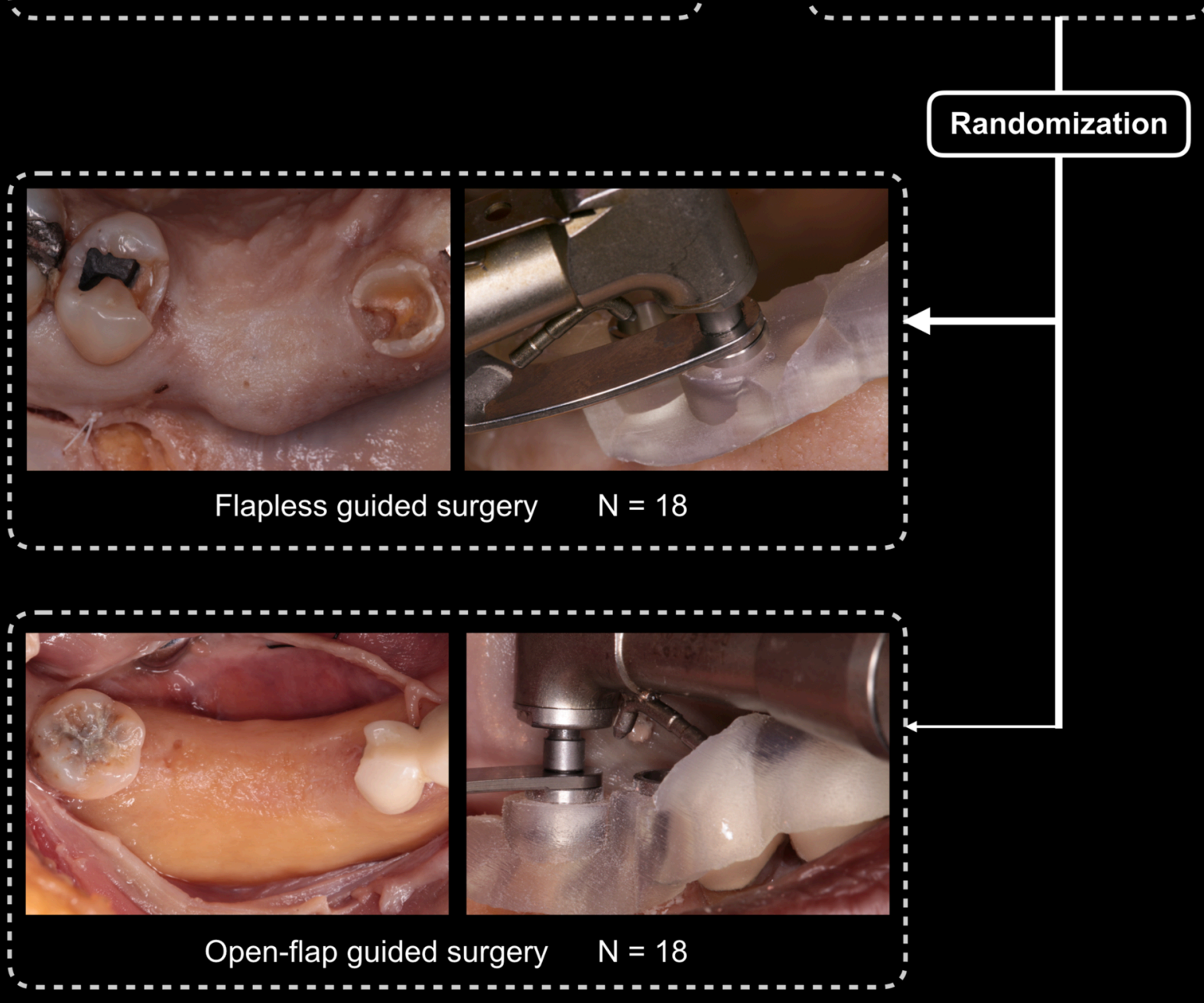

CID_12847_Figure 1.tif 


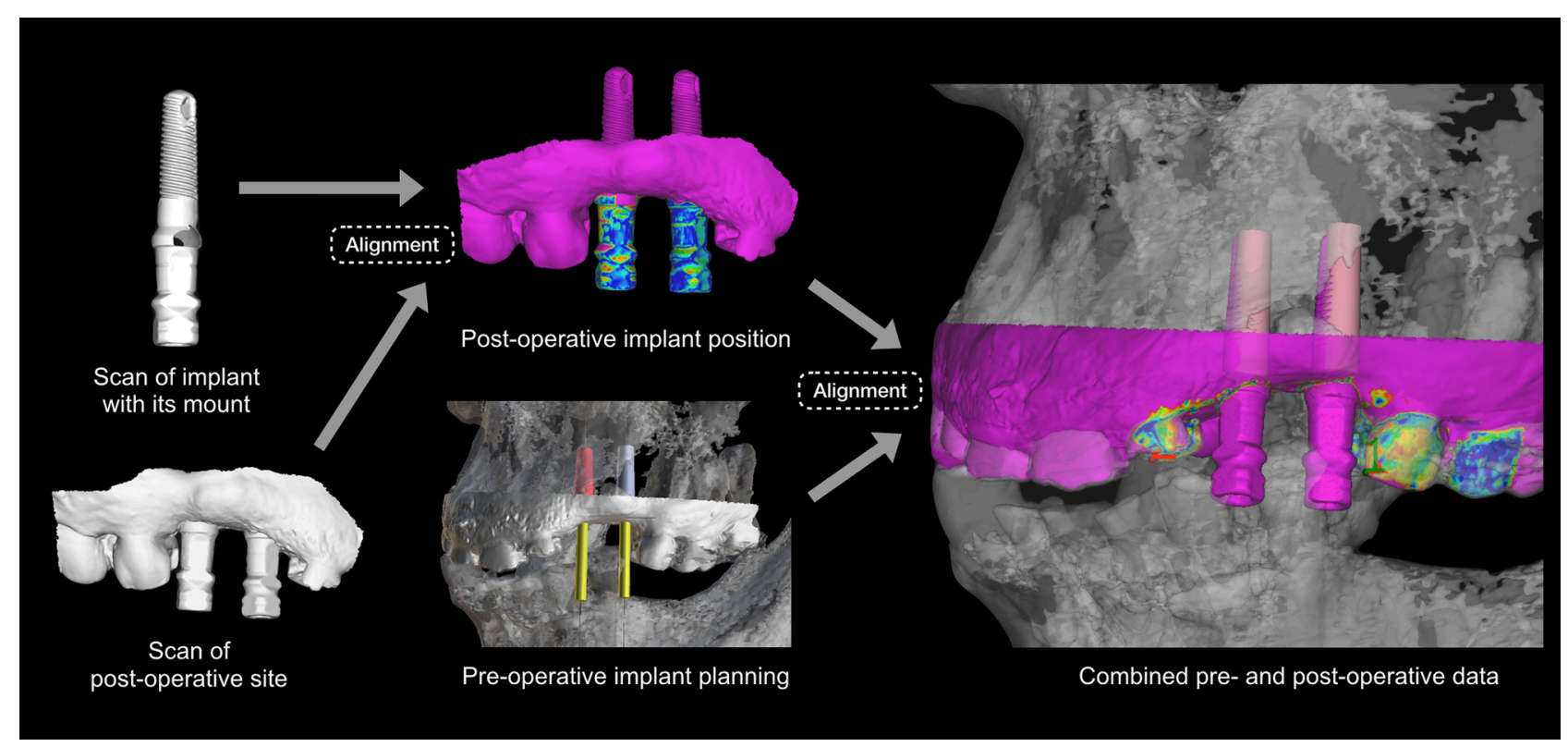

CID_12847_Figure 3.tif

This article is protected by copyright. All rights reserved. 


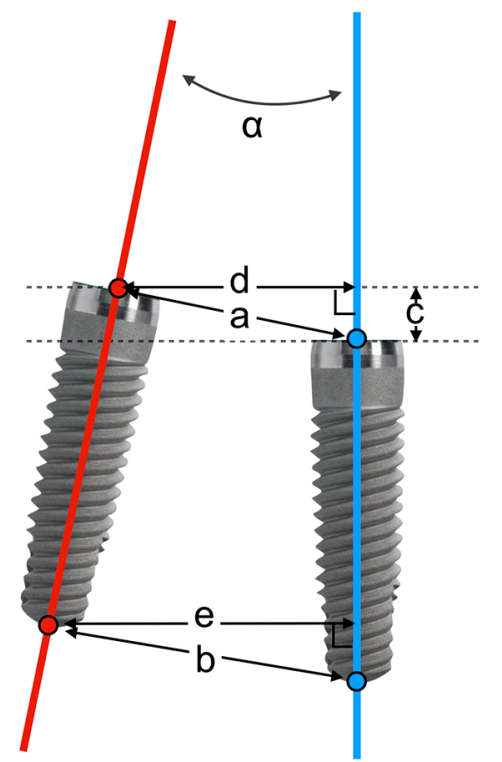

a: Global coronal deviation

b: Global apical deviation

C: Depth deviation

d: Lateral coronal deviation

e: Lateral apical deviation

a: Angular deviation

Actual position Planned position

CID_12847_Figure 4.tif

This article is protected by copyright. All rights reserved. 




This article is protected by copyright. All rights reserved. 